\title{
TOPOGRAPHY OF CARDIAC GANGLIA IN THE ADULT HUMAN HEART
}

Sanjay Singh, $\mathrm{MSc}^{\mathrm{a}}$

Patricia I. Johnson, $\mathrm{PhD}^{\mathrm{a}}$

Robert E. Lee, MD, $\mathrm{PhD}^{\mathrm{b}}$

Emilo Orfei, $\mathrm{MD}^{\mathrm{b}}$

Vassyl A. Lonchyna, $\mathrm{MD}^{\mathrm{c}}$

Henry J. Sullivan, MD

Alvaro Montoya, $\mathrm{MD}^{\mathrm{c}}$

Hoang Tran, $\mathrm{BS}^{\mathrm{a}}$

William H. Wehrmacher, MD

Robert D. Wurster, $\mathrm{PhD}^{\mathrm{a}}$
Published descriptions of the topography of cardiac ganglia in the human heart are limited and present conflicting results. This study was carried out to determine the distribution of cardiac ganglia in adult human hearts and to address these conflicts. Hearts obtained from autopsies and heart transplant procedures were sectioned, stained, and examined. Results indicate that the largest populations of cardiac ganglia are near the sinoatrial and atrioventricular nodes. Smaller collections of ganglia exist on the superior left atrial surface, the interatrial septum, and the atrial appendage-atrial junctions. Granglia also exist at the base of the great vessels and the base of the ventricles. The right atrial free wall, atrial appendages, trunk of the great vessels, and most of the ventricular myocardium are devoid of cardiac ganglia. These findings suggest modifcations to surgical procedures involving incisions through regions concentrated with ganglia to minimize arrhythmias and related complications. Repairs of septal defects, valvular procedures, and congenital reconstructions, such as the Senning and Fontan operations, involve incisions through areas densely populated with cardiac ganglia. The current standard procedure for orthotopic heart transplantation severs cardiac ganglia and their projections to nodal and muscular tissue. One modification of the current heart transplantation procedure, involving bicaval anastomosis, preserves atrial anatomy and the cardiac ganglia. Preservation of cardiac ganglia within the donor heart may provide additional neuronal substrate for intracardiac processing and targets for regenerating nerve fibers to the donor heart. (J Thorac Cardiovasc Surg 1996;112:943-53)
$E^{\mathrm{A}}$ fferent parasympathetic innervation of the human heart consists of preganglionic neurons located in the brain stem that project by the vagus nerve to postganglionic neurons within the cardiac ganglia. ${ }^{1-3}$ The postganglionic neurons project to the sinoatrial (SA) and atrioventricular (AV) nodes, as well as to the atrial and ventricular musculature. ${ }^{2-4}$ Activation of the parasympathetic pathway leads to

From the Neuroscience Program and Department of Physiology, the Department of Pathology, ${ }^{b}$ and the Department of Thoracic and Cardiovascular Surgery, ${ }^{\mathrm{c}}$ Loyola University Medical Center, Maywood, Ill.

Supported in part by a grant from the National Institutes of Health (27595) and by the James DePauw Fund.

Received for publication Oct. 11, 1995; revisions requested Dec. 26, 1995; revisions received Feb. 16, 1996; accepted for publication March 20, 1996.

Address for reprints: Robert D. Wurster, PhD, Physiology Department, Loyola University Medical Center, 2160 S. 1st Ave., Maywood, IL 60153-3500.

Copyright $(1996$ by Mosby-Year Book, Inc.

$0022-5223 / 96 \$ 5.00+0 \quad \mathbf{1 2 / 1 / 7 3 7 8 8}$ negative chronotropic, dromotropic, and inotropic changes in the heart. ${ }^{4,5}$ Afferent innervation consists of sensory neurons located in the dorsal root ganglia, nodose ganglia, and possibly the cardiac ganglia themselves. ${ }^{1,3,6,7}$ Sensory neurons influence the efferent parasympathetic pathway by the brain stem, spinal cord, and cardiac ganglia by central or local reflexes. ${ }^{1,3,6}$

Published descriptions of the topography of human cardiac ganglia are limited to early stages of development, ${ }^{8-11}$ to discrete regions of the adult heart, ${ }^{12-15}$ or present sparse and conflicting results. $^{8-11,16-20}$ In the prenatal heart, Francillon ${ }^{8}$ and Navaratnam ${ }^{9}$ described cardiac ganglia on the anterior surface of the left atrium but not lateral to the right pulmonary veins, whereas Smith $^{10}$ found the opposite results. In the neonate, King and Coakley $^{16}$ did not find ganglia on the superior left atrial surface or the atrial appendage-atrial junction, whereas Smith ${ }^{18}$ found ganglia in both these locations. Furthermore, Smith ${ }^{1,18}$ depicted ganglia extending to the apex of the neonate heart, where 
Table I. Clinical data and autopsy findings for cases from which complete hearts were obtained

\begin{tabular}{cccccl} 
Age $(\mathrm{yr})$ & Sex & $\begin{array}{c}\text { Heart weight } \\
(\mathrm{gm})\end{array}$ & $\begin{array}{c}\text { Left ventricular } \\
\text { thickness }(\mathrm{cm})\end{array}$ & $\begin{array}{c}\text { Right ventricular } \\
\text { thickness }(\mathrm{cm})\end{array}$ & \multicolumn{1}{c}{ Pathology and cause of death } \\
\hline 66 & $\mathrm{M}$ & 340 & 1.5 & 0.5 & Adenocarcinoma, lymphoma \\
64 & $\mathrm{~F}$ & 380 & 1.5 & 0.5 & Gastric carcinoma \\
42 & $\mathrm{~F}$ & 380 & 1.5 & 0.6 & Pulmonary infarction \\
37 & $\mathrm{~F}$ & 360 & 1.5 & 0.5 & Steatohepatitis, bowel resection \\
35 & $\mathrm{M}$ & 420 & 1.3 & 0.5 & Mycotic pneumonia \\
\hline
\end{tabular}

Davies, Francis, and King ${ }^{20}$ did not describe ganglia. In adults, King and Coakley ${ }^{16}$ demonstrated the presence of cardiac ganglia along the interatrial groove and interatrial septum, whereas Leonhardt ${ }^{17}$ did not find ganglia in these regions.

Many surgical procedures, including those for repair of atrial and ventricular septal defects or mitral and tricuspid valves, involve incisions through areas of high cardiac ganglia density. ${ }^{21,22}$ Procedures for the correction of transposition of the great arteries or tricuspid atresia, such as the Senning, Mustard, and Fontan operations, also result in trauma to the cardiac ganglia. ${ }^{21-24}$ In addition, the current standard technique for orthotopic heart transplantation, as described by Shumway and colleagues, ${ }^{25,26}$ requires transection of atrial tissue through areas densely populated with cardiac ganglia. Vagal activity, conveyed through the cardiac ganglia, is cardioprotective against certain arrhythmias, including supraventricular tachycardias, ${ }^{27,28}$ ventricular tachycardias, ${ }^{29,30}$ and ventricular fibrillation. ${ }^{31,32}$ Evidence also indicates that processing of sensory and motor information may occur entirely within the cardiac ganglia, without preganglionic vagal influences. ${ }^{6,7,33}$ Therefore, severing cardiac ganglia or their interconnections during surgery ${ }^{23,}, 28,34$ would diminish the ganglia's cardioprotective effects ${ }^{23,27-34}$ and reduce the substrate for neural processing ${ }^{6,7,33}$ within the heart.

Accurate identification of cardiac ganglia topography is a prerequisite for the design of surgical modifications aimed at minimizing trauma to the cardiac ganglia. However, reports in the literature are limited or conflicting. ${ }^{8-11,16-20}$ Therefore, the purpose of this study was to determine the topography of cardiac ganglia in the adult human heart and to address these conflicting reports. Gross dissection and light level histologic examination were used to generate topographic maps of the cardiac ganglia. Our results indicate that the largest populations of cardiac ganglia are concentrated near but not within the SA and AV nodes. Smaller collections are located on the superior and anterior left atrial surfaces, the atrial appendage-atrial junctions, the base of the great vessels, and the base of the ventricles. The right atrial free wall, trunk of the great vessels, the atrial appendages, and much of the ventricular myocardium are devoid of cardiac ganglia.

\section{Materials and methods}

Heart tissue procurement. Adult human heart tissue was obtained from autopsy cases and heart transplantation procedures at Loyola University Medical Center. The Institutional Review Board at Loyola University approved the protocol for removal of heart tissue not directly used during heart transplantation procedures. Five complete hearts from autopsy cases, and atrial or ventricular tissue from ten additional hearts, from both autopsy and heart transplantation cases, were examined.

Heart tissue was fixed and stored in $10 \%$ buffered formalin. Gross and histologic examination, including measurement of ventricular wall thickness and heart weight, was conducted to rule out any apparent cardiovascular pathology (Table I). Only normal, complete hearts were used in this study because several disease ${ }^{35-42}$ are known to be associated with changes in the cardiac ganglia. Two of the ten incomplete hearts, obtained from transplantation procedures, had coronary artery disease and ventricular dilatation. The remaining incomplete hearts were without apparent cardiovascular pathology.

Sampling and sectioning. Tissue was systematically removed from the complete and partial hearts in preparation for histologic procedures. The average surface area of the transmural sections was $2.90 \pm 0.69 \mathrm{~cm}^{2}$ (mean \pm standard deviation after dehydration) and ranged from 2.0 to $7.0 \mathrm{~cm}^{2}$. Atrial tissue samples were generally smaller than ventricular tissue samples, reflecting a finer sampling resolution. During dissection, tissue pieces were marked with a solvent-resistant dye (Sigma Chemical Co., St. Louis, Mo.) on the inferior and lateral edges to indicate their orientation within the intact heart. Several photographs were taken from different angles as each tissue section was removed. In addition, the tissue's origin was indicated on schematic diagrams of the heart. These measures were taken to ensure accuracy in topographic reconstruction after histologic examination for the cardiac ganglia.

In the five complete hearts, the entire epicardial surface, interatrial septum, and great vessels were sectioned 
and examined histologically. The atrioventricular and intraventricular septal regions were not examined. In seven of the ten incomplete hearts, the entire atria, excluding the atrial appendages and great vessels, were examined. Ventricular tissue adjacent to the coronary sulcus was sampled in these cases, although most of the ventricles were not. In one transplantation case, the entire right atrium was examined; in the final two, a rim of atrial tissue adjacent to the coronary sulcus and ventricular tissue was examined. The incomplete hearts were used principally to substantiate the findings from the five complete cases, rather than to provide original information.

Embedding and staining. Heart tissue was dehydrated through immersion in an ascending series of ethyl alcohol concentrations $(80 \%, 95 \%$, and $100 \%)$, cleared with $x y-$ lene, and immersed in warm paraffin. The procedure was automated using an Autotechnicon Mono processor (Technicon Instruments Co., Tarrytown, N.Y.) with 12 solution stations. Tissue was placed in each solution for 2 hours. Tissue pieces were blocked in paraffin using $20 \times$ $40 \mathrm{~mm}$ copper molds. Serial sections from the paraffin blocks were then generated with an American Optical 820 rotary microtome (American Optical Co., Buffalo, N.Y.) and mounted onto Corning $75 \times 38 \mathrm{~mm}$ glass slides (Corning, Inc., Corning, N.Y.). Atrial tissue was cut at 10 $\mu \mathrm{m}$; ventricular and great vessel tissue was cut at $20 \mu \mathrm{m}$.

Every fifteenth section from each serial set was stained with Harris' hematoxylin (Lerner Laboratories, Pittsburgh, Pa.) and eosin Y (Sigma). Slides were heated for 30 minutes at $60^{\circ} \mathrm{C}$ to enhance adhesion of the tissue to the slide, dewaxed in xylene, hydrated through a descending series of ethyl alcohol concentrations $(100 \%, 95 \%, 80 \%)$ and immersed in Harris' hematoxylin for 7 minutes. Tissue was differentiated with acid alcohol and a dilute ammonium solution. It was then stained with eosin $Y$ for 2 minutes. Finally, the tissue was dehydrated in an ascending series of ethyl alcohol concentrations (95\%, 100\%), cleared with xylene, and coverslipped with De-Pex medium (Biomedical Specialties, Inc., Santa Monica, Calif.).

Quantification and reconstruction. At $40 \times$ to $100 \times$ magnification, cardiac ganglia and nerves were clearly visible within the hematoxylin and eosin-stained tissue. Two experienced observers used a semiquantitative ordinal scale to rank the density of cardiac ganglia within the different tissue sections. The ordinal scale ranged from 0 to 5 as follows: 0 , no ganglia; 1 , very few ganglia; 2 , some ganglia; 3 , moderate collection of ganglia; 4 , dense population of ganglia; and 5, very dense population of ganglia. To eliminate potential bias, observers ranking the histology slides were blind to the tissues' origin. This was accomplished by labeling slides with unique numbers that did not reflect their epicardial or vascular source.

Reconstruction of the tissue pieces into topographic maps was performed with cross-reference to the original photographs and diagrams generated during the heart sectioning procedures. Orientation of the tissue pieces was verified with reference to the dye marks placed during gross sectioning of the hearts. Topographic maps were generated by representation of the ordinal data with solid circles on diagrams of the heart. Because the data were ordinal, circles reflected relative ganglia density rather than absolute numbers of ganglia.
Dense populations of ganglia were represented by a proportionally greater number of circles. A set of topographic maps reflecting the distribution of cardiac ganglia was the result of these procedures.

\section{Results}

Gross and histologic appearance. Cardiac ganglia were generally located in the epicardial layer and were surrounded by adipose tissue. Some ganglia also existed within the myocardial layer, but none were found in the endocardial or subendocardial layers. Large collections of cardiac ganglia were associated with epicardial fat, forming islands of adipose tissue on the myocardium. Previously these islands have been referred to as fat pads. ${ }^{3,23,43}$ A region lateral to the right pulmonary veins and another near the interatrial groove and coronary sulcus junction contained two distinct islands. Smaller islands existed on the superior and anterior left atrial surfaces. These islands serve as useful landmarks for visual identification of the cardiac ganglia. However, smaller collections of ganglia dispersed throughout other atrial and ventricular regions are independent of such adipose tissue islands.

Histologic examination revealed adipocytes surrounding the cardiac ganglia and a capsule of connective tissue around the ganglia (Fig. 1). Satellite cells and neuropil, consisting of axonal and dendritic arborizations, were found throughout the ganglia. Small ganglia contained as few as one neuron, whereas larger ganglia contained as many as 37 neurons in one $10 \mu \mathrm{m}$ thick cross-section. Ganglia were generally oval to circular in shape and branched in grapelike clusters from large-diameter, presumably vagal, nerves. Neurons were generally located at the periphery of the cardiac ganglia (Fig. 2). Multipolar neurons predominated, although pseudo-unipolar neurons were also present. Neurons were oval to circular in shape and contained eccentrically located nuclei. A thin capsule of connective tissue surrounded each neuron within the ganglia.

Atrial ganglia. In all hearts examined, the largest populations of cardiac ganglia were adjacent to, although not within, the nodal tissue of the heart (Table II). The SA node is located at the junction of the sulcus terminalis, the superior vena cava, and the right atrium. Ganglia in the region inferior and posterior to the SA node, termed para-SA nodal ganglia, extend from the right pulmonary veins to the sulcus terminalis (Figs. 3, 4, and 5). Some para-SA nodal ganglia extend laterally beyond the sulcus terminalis and approach the atrial appendage-atrial junction. Regions surrounding the 


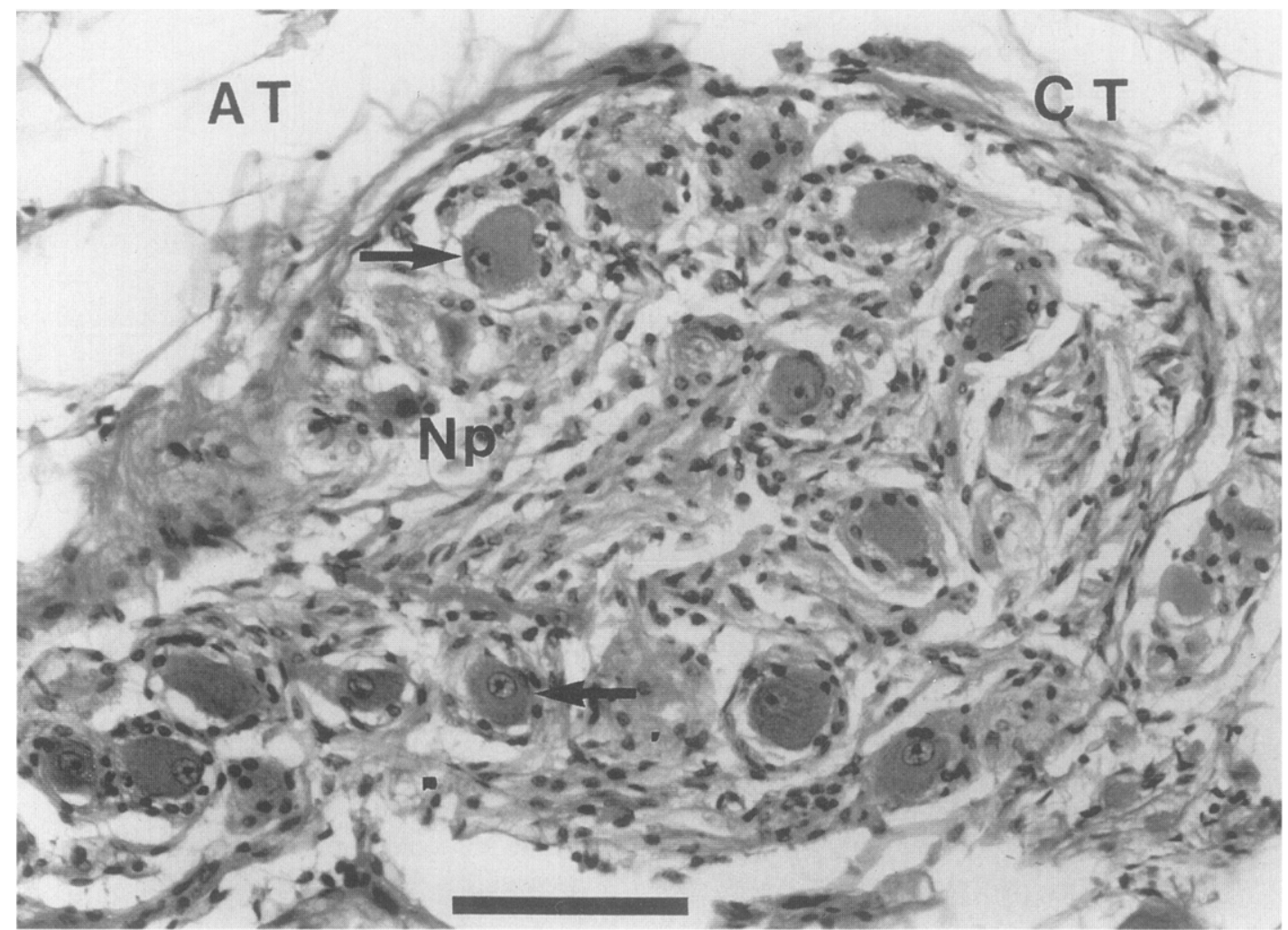

Fig. 1. Photomicrograph of a cardiac ganglion surrounded by epicardial adipose tissue $(A T)$ from the para-SA nodal ganglia of an adult human heart. Note the capsule of connective tissue (CT) around the ganglion and peripherally located postganglionic neurons (arrow). Neuropil $(\mathrm{Np})$ is found throughout the ganglion. Bar represents $100 \mu \mathrm{m}$.

para-SA nodal ganglia, such as the superior surface of the right pulmonary veins, the superior vena cava beyond its atrial junction, and the right atrial free wall lateral to the sulcus terminalis, were devoid of cardiac ganglia. The para-SA nodal ganglia were invariably rated as one of the two most densely populated collections of ganglia.

The AV nodal region contained the other densely populated collection of ganglia, referred to as the para- $A V$ nodal ganglia (Table II). The AV node is located medial to the coronary sinus in the interatrial septum and superior to the AV septum. The epicardial surface surrounding the AV node, near the interatrial groove and coronary sulcus junction, was studded with cardiac ganglia. The para-AV nodal ganglia extended into the interatrial septum, although fewer ganglia were present than on the epicardial surface. Para-AV nodal ganglia also extended laterally from the interatrial groove towards the inferior vena cava and left atrium along the coronary sulcus. Some ganglia were found inferior to the coronary sulcus within the epicardial fat overlying the coronary vasculature. Para-AV nodal ganglia did not extend far into the superior left atrial surface, beyond the inferior vena cava or extensively into the ventricles.

In addition to the para-SA and AV nodal ganglia, less dense populations of ganglia were found throughout other atrial regions (Table II and Figs. 3, 4 , and 5). Greater variability existed in the location of these smaller populations than in the para-SA and AV nodal collections. For example, the region inferior to the inferior vena cava and superior to the coronary sinus contained cardiac ganglia in all hearts examined, but this population was less discretely localized than the para-SA and AV nodal ganglia. Cardiac ganglia also existed on the superior and anterior left atrial surfaces and inferior and lateral to the left pulmonary veins. The atrial appendage-atrial junctions also contained cardiac ganglia. Regions within the atria that were devoid of 


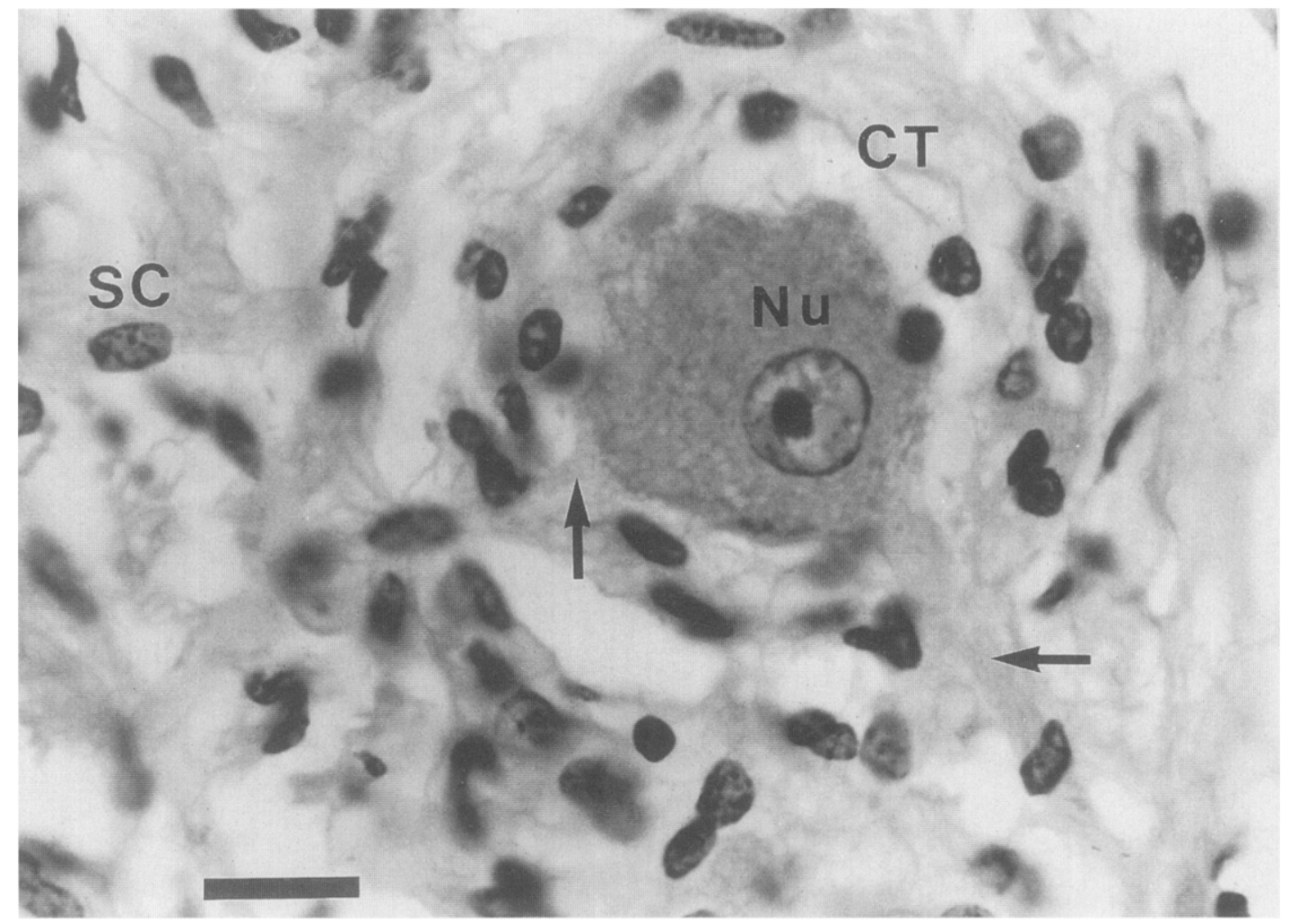

Fig. 2. Photomicrograph of a multipolar postganglionic neuron from the para-SA nodal ganglia of an adult human heart. Eccentrically located nuclei $(\mathrm{Nu})$ and nucleoli are clearly visible. Note the two neuronal processes (arrows) visible at this level. A thin layer of connective tissue (CT) surrounds the neuron, whereas satellite cells (SC) are intermingled within the neuropil. Bar represents $10 \mu \mathrm{m}$.

cardiac ganglia included the right atrial free wall lateral to the sulcus terminalis, the anterior and superior surfaces of the pulmonary veins, and the atrial appendages.

Great vessel ganglia. Cardiac ganglia were found primarily at the base of the aorta and pulmonary arteries near their junction with the ventricular myocardium (Figs. 4 and 5). The ascending aorta and aortic arch were devoid of ganglia, although largediameter nerves, presumably sympathetic and parasympathetic, were present along these vessels. Occasionally, small, isolated cardiac ganglia containing a few neurons were seen emanating from these nerves.

Unlike the aorta or pulmonary artery, the superior and inferior venae cavae had moderate collections of cardiac ganglia on their posterior surfaces. In particular, the superior vena cava near the junction of the right atrium and inferior to the SA node was moderately populated with ganglia. However, beyond the superior vena cava-atrial junction few ganglia were present on the superior vena cava surface. The inferior vena cava-atrial junction also contained a small population of ganglia. Ganglia were prevalent on the medial surface of the inferior vena cava, proximal to the para-AV nodal ganglia, and on the inferior surface proximal to the coronary sinus. Lateral portions of the inferior vena cava adjacent to the right atrial free wall were devoid of cardiac ganglia.

Ventricular ganglia. When cardiac ganglia were present in the ventricles, they were located primarily in the epicardial fat surrounding the coronary vasculature (Figs. 3, 4, and 5). Ganglia from the para-AV nodal collection extended into the ventricles just inferior to the coronary sulcus. Additional ganglia were found inferior to the coronary sinus and the base of the aorta and pulmonary artery. These ganglia were found in all of the hearts examined. Ganglia elsewhere in the ventricles were smaller and therefore contained fewer neurons. When observed, all ventricular cardiac ganglia were located near the coronary vessels and were variably distributed among the hearts examined. However, 
Table II. Ordinal ranking of cardiac ganglia density in different heart regions

\begin{tabular}{lccccc}
\hline & Heart & Heart & Heart & Heart & Heart \\
& 1 & 2 & 3 & 4 & 5 \\
\hline Atrial regions: & & & & & \\
RA, para-SA node & 5 & 4,5 & 4 & 4,5 & 5 \\
RA, para-AV node & 4 & 5 & 5 & 5 & 4,5 \\
RA, lateral free wall & 0 & 0 & 1 & 1 & 0 \\
RA, appendage & 0 & 0 & 1,0 & 0 & 0 \\
Interatrial septum & 3,2 & 2 & 3,2 & 2 & 2 \\
LA, superior wall & 2,3 & 3 & 3 & 2 & 2 \\
LA, anterior wall & 2 & 2 & 3,2 & 2 & 2 \\
LA, posterior wall & 2 & 3,2 & 3,2 & 2 & 3,2 \\
LA, appendage & 0 & 0 & 1 & 0 & 0 \\
Great vessels: & & & & & \\
Aorta, trunk & 0 & 0 & 0 & 0 & 0 \\
Pulmonary artery & 0,1 & 0 & 0 & 0 & 0 \\
SVC-atrial junction & 2 & 1 & 1 & 2,3 & 1 \\
IVC-atrial junction & 1,2 & 2,1 & 1 & 1 & 2,1 \\
Ventricular regions: & & & & & \\
Posterior, right base & 1 & 0 & 1,2 & 0,1 & 1 \\
Posterior, right apex & 0 & 0 & 0 & 0 & 0,1 \\
Posterior, left base & 0 & 0 & 1 & 1,0 & 0 \\
Posterior, left apex & 0 & 0 & 0 & 1,0 & 0 \\
Anterior, right base & 0,1 & 0,1 & 0 & 1 & 1 \\
Anterior, right apex & 0 & 0 & 0 & 0 & 0 \\
Anterior, left base & 0 & 0,1 & 0,1 & 0 & 1 \\
Anterior, left apex & 0 & 0 & 0 & 0 & 0 \\
\hline
\end{tabular}

Ordinal scale ranged from 0 to 5 as follows: 0 , No ganglia; 1 , very few ganglia; 2, some ganglia; 3, moderate collection of ganglia; 4, dense population of ganglia; 5 , very dense population of ganglia. Two values are listed only if ordinal rankings differed among the observers; in that circumstance, observer one is always listed first anid observer two, second. $R A$, Right atrium; $S A$, sinoatrial; $A V$, atrioventricular; $L A$, left atrium; $S V C$, superior vena cava; $I V C$, inferior vena cava.

the vast majority of the ventricular myocardium and coronary vasculature was devoid of cardiac ganglia.

\section{Discussion}

In this study we found the two largest populations of cardiac ganglia lateral to the right pulmonary veins and inferior to the superior vena cava, the para-SA nodal ganglia, and at the interatrial groove and coronary sulcus junction; the para-AV nodal ganglia. Smaller populations were found superior to the coronary sulcus and at the inferior vena cava-atrial junction, on the anterior and superior left atrial surfaces and lateral to the left pulmonary veins. In addition, cardiac ganglia were located at the base of the great vessels and ventricles. The right atrial free wall, atrial appendages, trunk of the great vessels, and the majority of the ventricular myocardium were devoid of cardiac ganglia.

Comparisons with previous studies. The findings from this study agree with previous studies reporting cardiac ganglia near the SA and AV nodes of the human heart. ${ }^{2,8-11,16-20}$ However, descriptions of the cardiac ganglia density and topography differ. For example, Leonhardt ${ }^{17}$ reported that similar cardiac ganglia densities exist near the SA node as on the superior left atrial surface. He also showed ganglia immediately lateral to the right pulmonary veins but did not show ganglia concentrated at the interatrial groove and coronary sulcus junction. In contrast, King and Coakley ${ }^{16}$ noted a high cardiac ganglia density near the SA node and the interatrial groove and coronary sulcus junction. Our results show ganglia concentrated in the para-SA nodal region, which is located inferior to King and Coakley's descriptions ${ }^{16}$ of this population and is more densely populated than Leonhardt's estimate ${ }^{17}$ of it. We also found ganglia concentrated in the para-AV nodal region, which is somewhat medial to King and Coakley's localization ${ }^{16}$ and is also more densely populated than Leonhardt's descriptions. ${ }^{17}$

Previous descriptions of cardiac ganglia topography outside the para-SA and AV nodal regions are also limited and contradictory. For example, King and Coakley ${ }^{16}$ described ganglia in the interatrial septum and the anterior right atrial surface; Leonhardt ${ }^{17}$, however, did not describe these areas. Alternatively, Leonhardt ${ }^{17}$ noted ganglia on the aorta, left pulmonary veins and caval surfaces, whereas King and Coakley ${ }^{16}$ did not examine these areas. In addition, Woollard $^{44}$ and Davies, Francis, and King ${ }^{20}$ described the lack of ganglia in the human ventricles, whereas others have reported the presence of cardiac ganglia. ${ }^{11,18,45,46}$ Our results show cardiac ganglia on the superior left atrial surface, the inferior and superior venae cavae, the interatrial septum, and interatrial groove. Furthermore, we found ganglia located primarily at the base of the great vessels rather than their trunks, contrary to Leonhardt's descriptions. ${ }^{17} \mathrm{We}$ also found small collections of cardiac ganglia near the ventricular coronary vasculature.

Methods used to determine cardiac ganglia topography are sparingly described in previous reports on the human heart. 8 -11, 16-20, 44-66 Dyes, schematic diagrams, and photography were apparently not used to document sectioning of the gross heart specimens. We found these procedures necessary for accurate reconstruction of the topography of cardiac ganglia after histologic examination. Differences in tissue reconstruction methods may explain some of the discrepancies in the literature. In addition, only one adult heart was examined by King and Coakley ${ }^{16}$ and, presumably, only one by Leonhardt. ${ }^{17}$ Given the moderate variability in distribution of the cardiac ganglia, a sample size of one could lead to erroneous generalizations. 


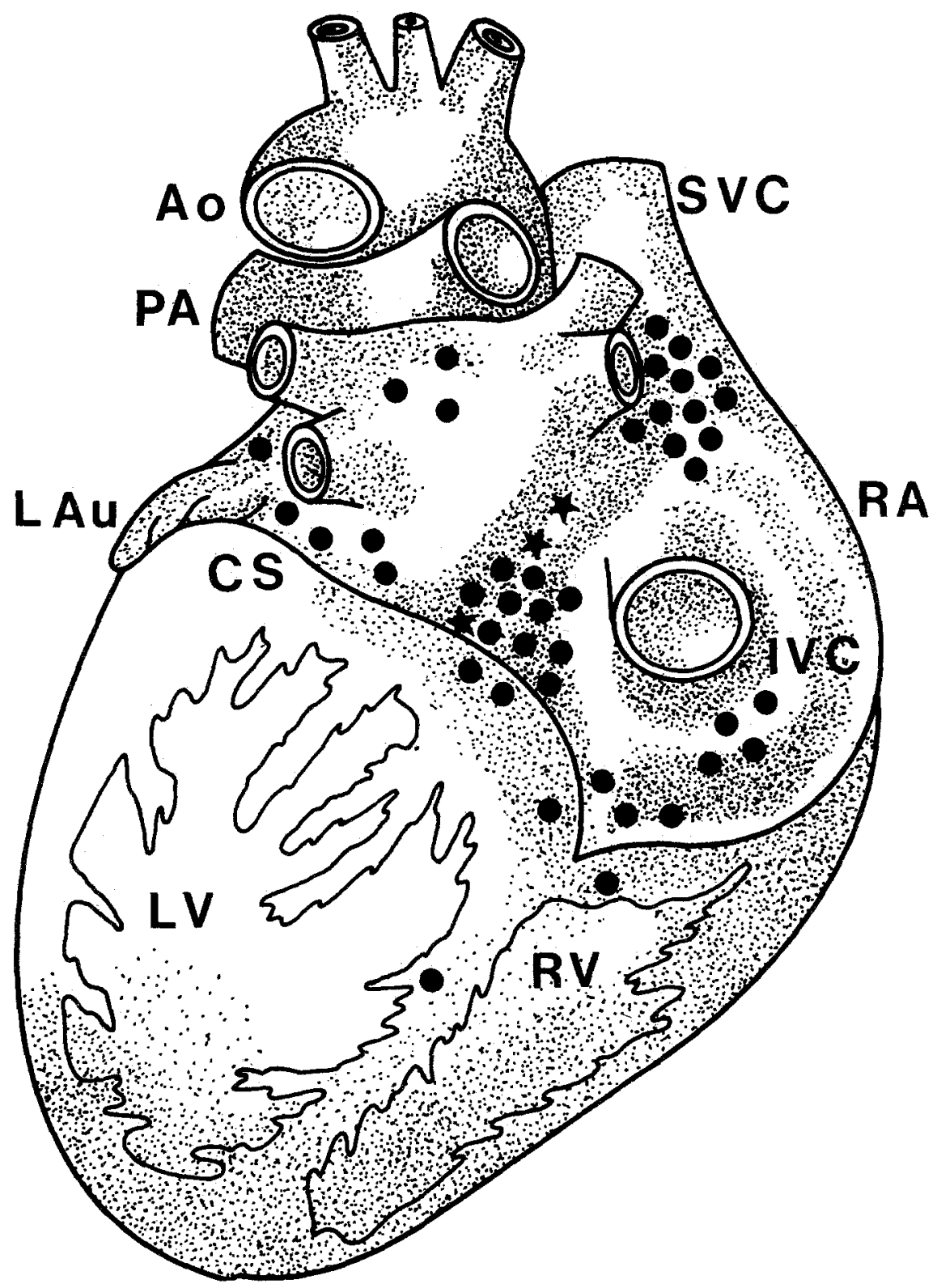

Fig. 3. Posterior view of an adult human heart showing topography of the cardiac ganglia (@). Para-SA nodal ganglia are concentrated primarily lateral to the right pulmonary veins. The para-AV nodal ganglia are on the epicardial surface superior to the coronary sulcus (CS) and within the interatrial septum ( $\star$ ). Smaller collections of ganglia are dispersed throughout both atria, including the region superior to coronary sinus, the superior left atrial surface, and lateral to the left pulmonary veins. The right atrial free wall $(R A)$ and the adventitia of the aorta $(A O)$ and pulmonary artery $(P A)$ do not contain cardiac ganglia. Most of the left ventricular $(L V)$ and right ventricular $(R V)$ myocardium is also devoid of ganglia. However, some ganglia exist inferior to coronary sulcus and occasionally in the fat surrounding the coronary vasculature. $S V C$, Superior vena cava; $I V C$, inferior vena cava; $L A u$, left atrial appendage.

Cardiovascular pathology and cardiac ganglia. Several cases of sudden cardiac death associated with arrhythmias have been reported in which no apparent pathology was present in the myocardium, nodal tissue or conductile tissue of the heart. ${ }^{35-37}$ However, examination of the para-SA nodal ganglia revealed localized inflammation within the ganglia that apparently led to the arrhythmias. ${ }^{35-37}$ Myocardial 


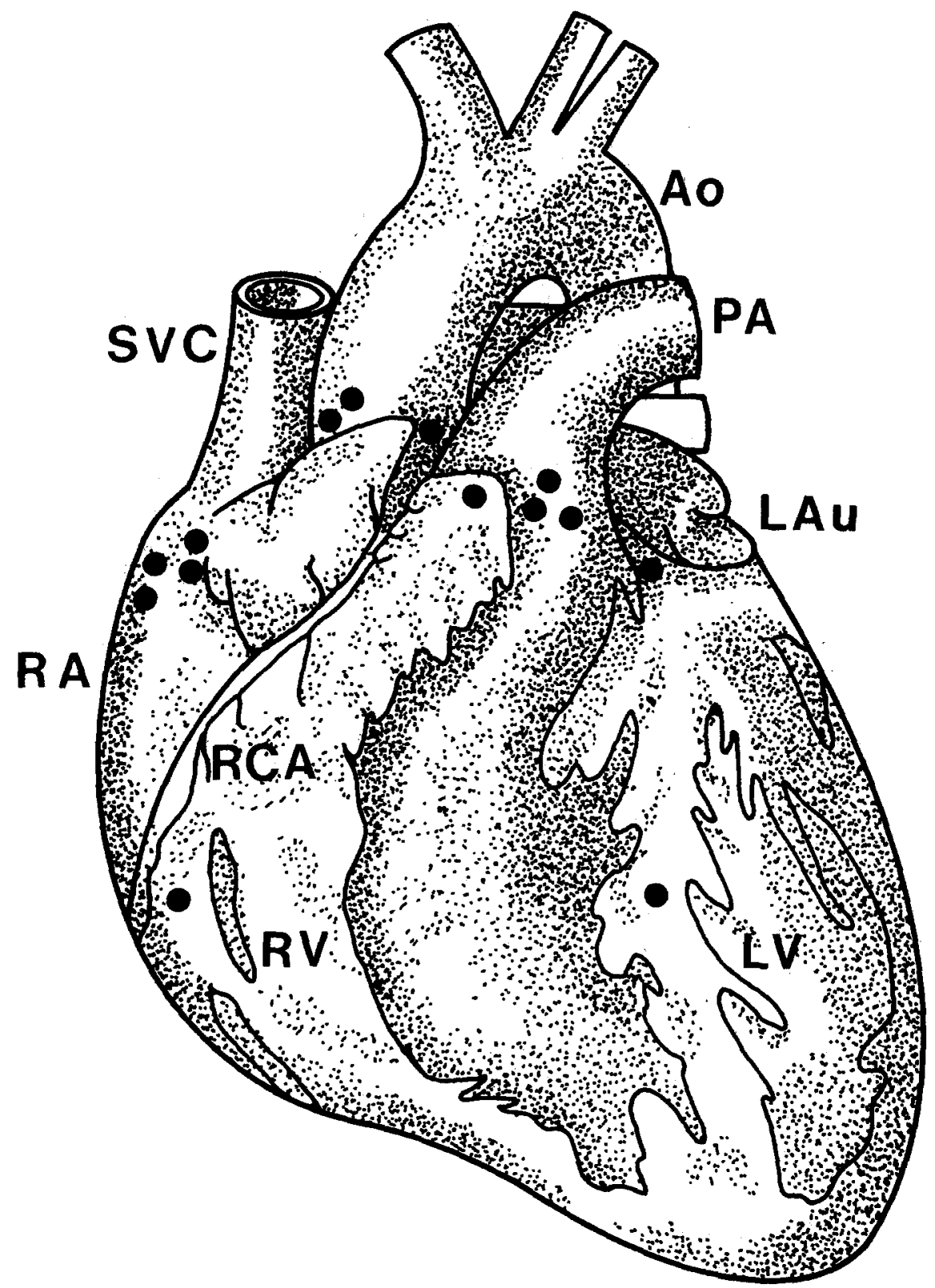

Fig. 4. Anterior view of an adult human heart showing topography of the cardiac ganglia (O). Ganglia are concentrated primarily at base of aorta $(A o)$ and pulmonary artery $(P A)$, and not on the ascending aorta or pulmonary trunk. Ganglia from the para-SA nodal collection can be seen extending to the right atrial $(R A)$ and atrial-appendage junction, whereas the lateral portions of the atrial appendages lack ganglia. Most of the left ventricular $(L V)$ and right ventricular $(R V)$ myocardium is devoid of cardiac ganglia, although some can be found near the coronary vasculature. $S V C$, Superior vena cava; $L A u$, left atrial appendage; $R C A$, right coronary artery.

infarctions or pericarditis can damage secondarily the cardiac ganglia and also result in electrical anomalies and arrhythmias. ${ }^{36-37}$ In patients with diabetes, atrophy and loss of Nissl substance in ganglionic neurons has been reported. ${ }^{42}$ Furthermore, changes in neuro- nal morphology ${ }^{41}$ and reductions of cardiac ganglia density ${ }^{14}$ have been linked with aging. However, routine pathologic examination of the heart generally does not include assessment of the cardiac ganglia. We suggest that the para-SA or AV nodal ganglia be 


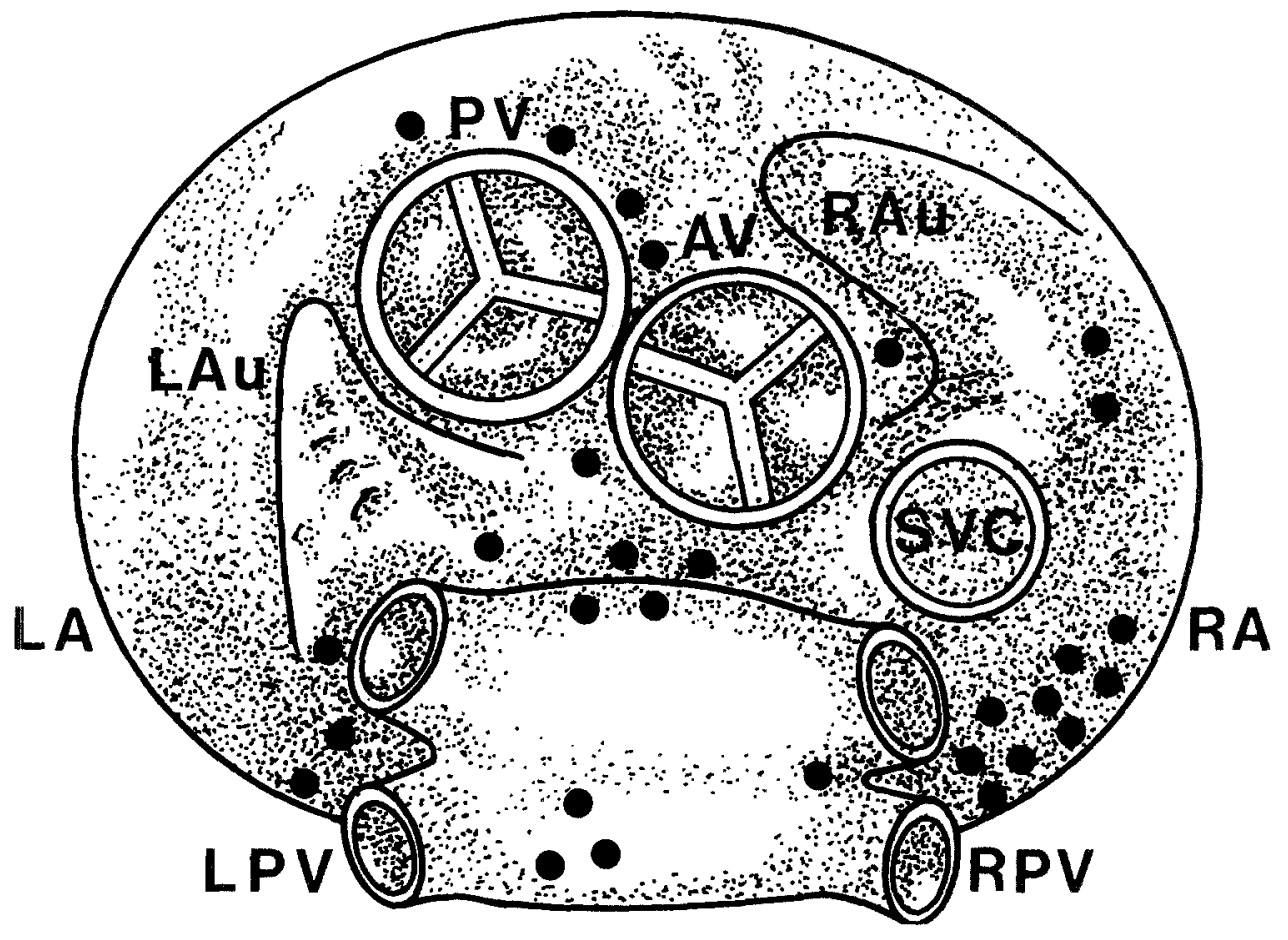

Fig. 5. Superior view of an adult human heart showing topography of the cardiac ganglia ( The aorta and pulmonary artery have been removed to reveal the aortic $(A V)$ and pulmonary valves $(P V)$. From this perspective, the para-SA node ganglia can be seen lateral to the right pulmonary veins ( $R P V)$, with some ganglia extending toward the right atrial appendage $(R A u)$. Ganglia on the superior and anterior left atrial surfaces $(L A)$ as well as the base of the great vessels are depicted. Ganglia also exist lateral to the left pulmonary veins $(L P V)$ and extend to the left atrial appendage ( $L A u)$. $R A$, Right atrium.

examined histologically for correlates with systemic and cardiovascular pathology.

Chagas' cardiomyopathy results in a dramatic loss of neurons within cardiac ganglia and, therefore, autonomic tone favoring sympathetic activity. ${ }^{12,13}$ This autonomic imbalance may contribute to the severe myocardial hypertrophy associated with Chagas' cardiomyopathy. ${ }^{13,14,38}$ Whether depopulation of cardiac ganglia also occurs in dilated cardiomyopathy is currently debated. One group ${ }^{15}$ reported significant decreases in the number of cardiac ganglia, whereas another ${ }^{40}$ reported no such changes in hearts with dilated cardiomyopathy. Both groups used similar methods of enumerating ganglia in tissue strips between the superior and inferior venae cavae..$^{2-15,40}$ However, because the number of ganglia reported in normal hearts varied by almost an order of magnitude between these two studies, results from hearts with dilated cardiomyopathy are difficult to interpret. ${ }^{15,40}$ Our results indicate that the medial boundary of the tissue strips used in these studies lies in a region that is densely populated with ganglia. Therefore, variation in the medial boundary by even a few millimeters would lead to large differences between estimates of neuronal numbers. To increase reproducibility of neuronal estimates, we suggest circumferential sampling and enumeration of the entire, discrete para-SA nodal ganglia population.

Cardiovascular surgery and cardiac ganglia. Increased vagal tone, often suggested to be cardioprotective, ${ }^{27-32,34}$ can terminate paroxysmal supraventricular $^{27,28}$ and ventricular tachycardias ${ }^{29,30}$ as well as prevent the induction of ventricular tachycardias ${ }^{29,30}$ and fibrillation. ${ }^{31,32}$ Vagal activation has also been shown to confer protection against sudden cardiac death during acute myocardial ischemia. ${ }^{32}$ Normally, vagal regulation of the SA and $\mathrm{AV}$ nodes is mediated by parallel pathways through the para-SA and $\mathrm{AV}$ nodal ganglia, ${ }^{3,4,23,43}$ respectively. However, surgi$\mathrm{cal}^{23,28}$ or catheter ablation ${ }^{34}$ of the para-SA nodal ganglia can lead to intravagal and autonomic imbalances, pacemaker instability, ${ }^{23,28} \mathrm{AV}$ nodal block, ${ }^{28}$ and persistent sinus tachycardias. ${ }^{34}$ Surgical trauma to cardiac ganglia may also lead to withdrawal of cardio- 
protective vagal influences and predisposition toward arrhythmogenesis. ${ }^{23,28,34}$ Therefore, preservation of cardiac ganglia during surgery has the advantage of maintaining parallel vagal regulation of the SA and AV nodes, sympathetic-parasympathetic balance, and electrical stability of the heart.

The current standard procedure for heart transplantation $^{25,26}$ results in extensive trauma to the cardiac ganglia and an abnormal atrial geometry prone to arrhythmias and thrombus formation. ${ }^{47.52}$ Recently, several groups have implemented a modified procedure for orthotopic heart transplantation that involves bicaval anastomosis. ${ }^{48-52}$ With this procedure, normal atrial anatomy is maintained and the para-SA and $\mathrm{AV}$ nodal ganglia remain undamaged. With respect to the standard procedure, increased sinus rhythm recovery and decreased regurgitation, atrial arrhythmias, and overall morbidity and mortality have been reported with the bicaval anastomosis technique. ${ }^{48-52}$ We believe that cardiac ganglia preservation contributes, in part, to the enhanced electrical stability and mechanical performance of these donor hearts. Furthermore, sympathetic, ${ }^{53-57}$ parasympathetic, ${ }^{58,59}$ and sensory ${ }^{60}$ reinnervation reportedly occurs after transplantation. Therefore, preservation of cardiac ganglia within the donor heart provides additional neuronal targets for regenerating nerve fibers. In addition, neural processing seems to occur entirely within the cardiac ganglia, $, 6,7,33$ without preganglionic vagal influence, and, thus, cardiac ganglia may provide intrinsic neural regulation of an otherwise centrally denervated donor heart.

\section{Conclusions}

The topography of cardiac ganglia in the adult human heart is not common basic or clinical knowledge, due in part to limited or inconsistent reports. However, cardiac ganglia are integral to the physiology and pathophysiology of the heart and therefore warrant further examination. In particular, correlations of changes in cardiac ganglia with pathology may help unravel mechanisms underlying systemic and cardiovascular diseases and potentially offer approaches for therapy. Finally, surgical procedural modifications minimizing surgical trauma to the cardiac ganglia may lead to enhanced electrical stability of the heart and better postoperative prognosis for patients.

We thank George Kaye, Betty Eberly, and Maria Weber for their assistance in obtaining and staining the human heart tissue. We also thank Sulman Masud, MD, for his assistance with the diagrams of the heart.

\section{REFERENCES}

1. Spyer KM, Brooks PA, Izzo PN. Vagal preganglionic neurons supplying the heart. In: Levy MN, editor. Vagal control of the heart: experimental basis and clinical implications. Armonk (NY): Futura Publishing, 1994:45-64.

2. Rossi L. Histology of cardiac vagal innervation in man. In: Levy MN, editor. Vagal control of the heart: experimental basis and clinical implications. Armonk (NY): Futura Publishing, 1994:3-20.

3. Randall WC, Wurster RD. Peripheral cardiac innervation of the heart. In: Levy MN, editor. Vagal control of the heart: experimental basis and clinical implications. Armonk (NY): Futura Publishing, 1994:613-36.

4. Carlson MD, Geha AS, Hsu J, Martin SD, Levy MN, Jacobs G. et al. Selective stimulation of parasympathetic nerve fibers to the human sinoatrial node. Circulation 1992;85:1311-7.

5. Levy MN, Martin P. Parasympathetic control of the heart. In: Randall WC, editor. Nervous control of cardiovascular function. New York: Oxford University Press, 1984:68-94.

6. Ardell JL. Structure and function of mammalian intrinsic cardiac neurons. In: Armour JA, Ardell JL, editors. Neurocardiology. New York: Oxford University Press, 1994:95-114.

7. Armour JA. Peripheral autonomic neuronal interactions in cardiac regulation. In: Armour JA, Ardell JL, editors. Neurocardiology. New York: Oxford University Press, 1994:219-44.

8. Francillon MR. Zur topographie der Ganglien des menschlichen Herzens. Z Anat Entwgesch 1928;85:131-45.

9. Navaratnam V. Development of the nerve supply to the human heart. Br Heart J 1965;27:640-50.

10. Smith RB. Intrinsic innervation of the human heart in foetuses between $70 \mathrm{~mm}$ and $420 \mathrm{~mm}$ crown-rump length. Acta Anat 1971;78:200-9.

11. Smith RB. The occurrence and location of intrinsic cardiac ganglia and nerve plexuses in the human neonate. Anat Rec 1970;169:33-40.

12. Koberle F. Cardiopathia parasympathicopriva. Munch Med Wochenschr 1959;101:1308-10.

13. Oliveira JS. A natural human model of intrinsic heart nervous system denervation: Chagas' cardiopathy. Am Heart J 1985;110:1092-8.

14. Amorim DS, Olsen EG. Age-associated changes in the number of neurons in the right atrium. Braz J Med Biol Res $1990 ; 23: 21-8$

15. Amorim DS, Olsen EG. Assessment of heart neurons in dilated (congestive) cardiomyopathy. Br Heart J 1982;47:11-8.

16. King TS, Coakley JB. The intrinsic nerve cells of the cardiac atria of mammals and man. J Anat 1958;92:353-76.

17. Leonhardt H. Internal organs. 3rd ed. Stuttgart: Georg Thieme Verlag, 1986:18-9.

18. Smith RB. Observations on nerve cells in human, mammalian and avian cardiac ventricles. Anat Anz 1971;129:437-44.

19. McFarland J, Anders A. The morbid histology of the cardiac nervous ganglia. J Med Res 1913;27:425-35.

20. Davies F, Francis ET, King TS. Neurological studies of the cardiac ventricles of mammals. J Anat 1952;86:130-43.

21. Khonsari S. Cardiac surgery: safeguards and pitfalls in operative technique. Rockville (MD): Aspen Publishers, 1988.

22. Bharati S, Lev M, Kirklin JW. Cardiac surgery and the conduction system. 2nd ed. Mount Kisco (NY): Futura Publishing, 1992:21-74.

23. Randall WC, Wurster RD, Duff M, O'Toole MF, Wehrmacher W. Surgical interruption of postganglionic innervation 
of the sinoatrial nodal region. $\mathbf{J}$ Thorac Cardiovasc Surg 1991;101:66-74.

24. Randall WC, Wehrmacher WH. Early and late arrhythmias after the Fontan operation: predisposing factors and clinical consequences [letter]. Br Heart J 1993;69:572.

25. Lower RR, Stofer RR, Shumway NE. Homovital transplantation of the heart. J Thorac Cardiovasc Surg 1961;41:196-24.

26. Shumway NE, Lower RR, Stofer RC. Transplantation of the heart. Adv Surg 1966;2:265-84.

27. Waxman MB, Wald RW, Sharma AD, Heuta F, Cameron DA. Vagal techniques for termination of paroxysmal supraventricular tachycardia. Am J Cardiol 1980;46:655-64.

28. Randall DC, Randall WC, Brown DR, Yingling JD, Raisch RM. Heart rate control in awake dog after selective SA-nodal parasympathectomy. Am J Physiol 1992;262(4 Pt 2):H1128-35.

29. Waxman BM, Wald RW. Termination of ventricular tachycardia by an increase in cardiac vagal drive. Circulation 1977;56:385-90.

30. Waxman MB, Cameron D, Wald RW. Vagal activity and ventricular tachyarrhythmias. In: Levy MN, editor. Vagal control of the heart: experimental basis and clinical implications. Armonk (NY): Futura Publishing, 1994:579-612.

31. De Ferrari GM, Vanoli E, Schwartz PJ. Vagal activity and ventricular fibrillation. In: Levy MN, editor. Vagal control of the heart: experimental basis and clinical implications. Armonk (NY): Futura Publishing, 1994:613-36.

32. Hull SS, Vanoli E, Adamson PB, Verrier RL, Foreman RD, Schwartz PJ. Exercise training confers anticipatory protection from sudden death during acute myocardial ischemia. Circulation 1994;89:548-52.

33. Murphy DA, O'Blenes S, Hanna BD, Armour JA. Capacity of intrinsic cardiac neurons to modify the acutely autotransplanted mammalian heart. J Heart Lung Transplant 1994;13:847-56.

34. Kocovic DZ, Harada T, Shea JB, Soroff D, Freidman PL. Alteration of heart rate and of heart rate variability after radiofrequency catheter ablation of supraventricular tachycardia: delineation of parasympathetic pathways in the human heart. Circulation 1993;88:1671-81.

35. James TN, Zipes MD, Finegan RE, Eisele JW, Carter JE. Cardiac ganglionitis associated with sudden unexpected death. Ann Intern Med 1979;91:727-30.

36. James TN. Primary and secondary cardioneuropathies and their functional significance. J Am Coll Cardiol 1983;2:983-1002.

37. James TN. Clinical significance of neural control of the heart. In: Randall WC, editor. Nervous control of cardiovascular function. New York: Oxford University Press, 1984:435-64.

38. Davila DF, Donis JH, Torres A, Gottberg CF, Rossell O. Cardiac parasympathetic innervation in Chagas' heart disease. Med Hypotheses 1991;35:80-4.

39. Amorim DS, Dargie HJ, Heer K, Brown M, Jenner D, Olsen $E G$, et al. Is their autonomic impairment in congestive (dilated) cardiomyopathy? Lancet 1981;1:525-7.

40. Ray R, Bhusnurmath B, Datta BN, Kaur S. Intracardiac autonomic ganglion cells in leprosy and dilated cardiomyopathy. Ind Heart J 1993;45:45-7.

41. Shlyapnikov VN, Uglova MV. Morphometric indices of human cardiac neurons during postnatal development. Neurosci Behav Physiol 1978;9:306-11.

42. Tsujimura T, Nunotani H, Fushimi H, Inoue T. Morphological changes in autonomic ganglionic cells of the heart in diabetic patients. Diabetes Res Clin Pract Suppl 1986;2:133-7.
43. Ardell JL, Randall WC. Selective vagal innervation of sinoatrial and atrioventricular nodes in canine heart. Am J Physiol 1986;251(4 Pt 2):H764-73.

44. Woollard HH. The innervation of the heart. J Anat $1926 ; 60$ : 345-73.

45. Lee R. On the ganglia and nerves of the heart. Philos Trans R Soc Lond B Biol Sci 1849; (Pt 1):43-8.

46. Morison AB. Note on the innervation of the ventricle of the human heart. J Anat 1926;60:143-6.

47. Pavri BB, O'Nunain SS, Newell JB, Ruskin JN, Dec GW. Prevalence and prognostic significance of atrial arrhythmias after orthotopic cardiac transplantation. J Am Coll Cardiol 1995;25:1673-80.

48. Deleuze PH, Benvenuti C, Mazzucotelli JP, Perdrix C, Le Besnerais $\mathrm{P}$, Mourtada $\mathrm{A}$, et al. Orthotopic cardiac transplantation with direct caval anastomosis: is it the optimal procedure? J Thorac Cardiovasc Surg 1995;109:731-7.

49. Sarsam MA, Campbell CS, Yonan NA, Deiraniya AK, Rahman AN. An alternative surgical technique in orthotopic cardiac transplantation. J Card Surg 1993;8:344-9.

50. El Gamel A, Yonan NA, Grant S, Deiraniya AK, Rahman AN, Sarsam MA, et al. Orthotopic cardiac transplantation: a comparison of standard and bicaval Wythenshawe techniques. J Thorac Cardiovasc Surg 1995;109:721-30.

51. El Gamel A, Yonan NA, Rahman AN, Deiraniya AK, Campbell CS, Sarsam MA. The clinical benefit of the bicaval technique for cardiac transplantation. J Thorac Cardiovasc Surg 1995;109:1257-9.

52. Dreyfus G, Jebara V, Mihaileanu S, Carpentier AF. Total orthotopic heart transplantation: an alternative to the standard technique. Ann Thorac Surg 1991;52:1181-4.

53. Wharton J, Polak JM, Gordon L, Banner NR, Springall DR, Rose $\mathrm{M}$, et al. Immunohistochemical demonstration of human cardiac innervation before and after transplantation. Circ Res 1990;66:900-12.

54. Burke MN, McGinn AL, Homans DC, Christensen BV, Kubo $\mathrm{SH}$, Wilson RF. Evidence for functional sympathetic reinnervation of left ventricle and coronary arteries after orthotopic cardiac transplantation in humans. Circulation 1995;91:72-8.

55. De Marco T, Dae M, Yuen-Green MS, Kumar S, Sudhir K, Keith F, et al. Iodine-123 metaiodobenzylguanidine scintigraphic assessment of the transplanted human heart: evidence for late reinnervation. J Am Coll Cardiol 1995;25:927-31.

56. Wilson RF, Christensen BV, Olivari MT, Simon A, White CW, Laxson DD. Evidence for structural sympathetic reinnervation after orthotopic heart transplantation in humans. Circulation 1991;83:1210-20.

57. Wilson RF, Laxson DD, Christensen BV, McGinn AL, Kubo SH. Regional differences in sympathetic reinnervation after human orthotopic cardiac transplantation. Circulation 1993;88: 165-71.

58. Bernardi L, Valle F, Leuzzi S, Rinaldi M, Marchesi E, Falcone $\mathrm{C}$, et al. Non-respiratory components of heart rate variability in heart transplant recipients: evidence of autonomic reinnervation? Clin Sci 199:; 86:537-45.

59. Fitzpatrick AP, Banner N, Cheng A, Yacoub M, Sutton R. Vasovagal reactions may occur after orthotopic heart transplantation. J Am Coll Cardiol 1993;21:1132-7.

60. Stark RP, McGinn AL, Wilson RF. Chest pain in cardiactransplant recipients: evidence of sensory reinnervation after cardiac transplantation. N Engl J Med 1991;324:1791-4. 